\title{
ASPECTOS DO FUNDAMENTO DO ESPERANTO
}

\author{
Geraldo Mattos \\ Universidade Federal do Paraná
}

RESUMO

O Esperanto foi lançado em 1887 através de cinco pequenos livros em russo, polonês, francês, inglês e alemão. O movimento cresceu e em 1905 reuniu em Boulogne-surMer o primeiro congresso esperantista: o pouco mais de milhar de participantes votou a Declaração de Boulognesur-Mer, que era a aceitação de um Fundamento do Esperanto, que consistia de uma gramática de 16 regras, de uma série de exercícios e de um dicionário com 2500 ver. betes aproximadamente. Esse conjunto foi declarado intocável e imutável para garantir a unidade da lingua. Entretanto, vemos hoje que o Fundamento do Esperanto tem uma parte de língua e outra de gramática. Esta não pode ser considerada intocável, porque os conhecimentos cien. tíficos sobre a lingua evoluiram consideravelmente neste século. Este artigo pretende explorar uma das deficiências teóricas dessa parte puramente gramatical do Fundamento do Esperanto e propor uma solução para ela.

\section{Introdução.}

O Esperanto é uma língua de origem artificial, lançada ao mundo em 1887 por meio de cinco livretos respectivamente em russo, polonês, alemão, francês e inglês, em que aparecem a gramática da lingua, algumas traduções, alguns originais e um pequeno dicionário de pouco mais de novecentas palavras, que constituem até hoje o núcleo vocabular do Esperanto.

Poucos anos depois, a língua estava suficientemente conhecida e divulgada no mundo para fazer-se o primeiro congresso mundial de Esperanto em Bolonha-Sobre-o-Mar no ano de 1905. O milhar de esperantistas, que se reuniram naquela cidade francesa, discutiram as possíveis mudanças de língua que seriam implicadas pelo emprego da lingua em escala 
mundial e, sob proposta do criador do Esperanto, estabeleceram um Fundamento do Esperanto, que foi declarado intocável para garantir uma única linha de evolução da língua. Esse fundamento continha a gramática original de dezesseis regras, quarenta e dois exercícios e um dicionário de duas mil e quinhentas palavras traduzidas para as cinco linguas originais do primeiro livro.

O compromisso do primeiro congresso se manteve aceito por todos até os dias de hoje. Entretanto, existem nele duas partes bem distintas:

a) um conteúcio de lingua.

i) um conteuido de gramática.

O conteúdo de língua é inatacável, mas o conteúdo de gramática, redigido no fim do século passado, deve ser atualizado.

Este artigo pretende analisar um erro de conceito puramente gramatical que repercute no dicionário da língua, mas não na própria lingua.

2. Estrutura da palavra esperantista.

O Esperanto é uma língua com uma morfologia riquíssima, embora sujeita a regras muito singelas, absolutamente sem exceções.

2.1 Coesão de morfemas.

A palavra esperantista, sempre paroxitona, é uma estrutura de três elementos principais:

Dis ir i - ir em várias direçōes: separar-se.

Hom ar o - conjunto de homens: humanidade.

morfema de classe de palavra morfema essencial

morfema prefixal

\subsection{Classe de morfemas.}

Cada raiz tem uma classe definida:

Hom o

sufixo de substantivo

raiz substantiva

Bon a $(0=0)$

sufixo de adjetivo

raiz adjetiva 


\section{$\operatorname{Ir} i$}

sufixo de verbo

raiz verbal

O conhecimento da classe da raiz é necessária para proceder-se à formaçāo de novas palavras.

2.3 Ocupantes das funções vocabulares.

A palavra esperantistas tem comumente uma funçāo essencial (E) e duas acidentais $(A)$ :

Dis ir i

$\overline{A_{1}} \bar{E} \overline{A_{2}}$

A função $\left(A_{1}\right)$ é ocupada regularmente por prefixos:

Dis ir $\mathrm{i} \quad$ - ir em várias direções: separar-se.

Ek ir i - ir de repente: partir.

$\mathrm{El}$ ir $\mathrm{i}$ - ir de dentro de: sair.

En ir i - ir para dentro de: entrar.

Kun ir i - ir junto: acompanhar.

Tra ir i - ir através de: atravessar.

$\mathrm{A}_{1}$

A funçāo ( $E$ ) é ocupada por uma classe aberta de raizes: Bros o $(s=\mathbf{s s})$ - escova.

Lert a $(\mathrm{e}=\hat{\mathrm{e}})$ - ágil.

Komb i - pentear.

$\mathrm{E}$

A função $\left(\mathrm{A}_{2}\right)$ é ocupada regularmente por sufixos:

Kron 0

Util a

- coroa.

Dorm i

- útil.

Nepr e

- dormir.

- necessariamente.

$\overline{\text { A. }}$

3. Formação de palavras.

As novas palavras são formadas regularmente pela subordinação de palavras ou locuçōes nas posições das funções $\left(A_{1}\right)$ e $(E)$.

Aqui interessa-nos apenas a subordinação de palavra na função essencial, absolutamente regular no significado da pa. lavra derivada, desde que seja conhecida a classe da raiz.

3.1 Raiz substantiva.

A raiz substantiva deriva regularmente adjetivos, verbos e advérbios com significado rigorosamente determinado. 
3.1.1 Adjetivos derivados.

$O$ adjetivo derivado de raiz substantiva indica uma relação de pertinência.

A produção da língua alinha os morfemas:

$$
\begin{aligned}
& \frac{\text { Dom }}{E} \frac{o}{A_{2}} \\
& \frac{\text { Dom }}{E} \frac{O}{A_{2}} \\
& E
\end{aligned}
$$

- casa.

- relativo a casa: doméstico.

A execução da língua implica a presença de uma variante zero para o sufixo de classe substantiva:

$$
\frac{\frac{\text { Dom }}{\mathrm{E}} \frac{\phi}{\mathrm{A}_{2}}}{\mathrm{E}} \frac{\mathrm{a}}{\mathrm{A}_{2}}
$$$$
\text { - doma. }
$$

\subsubsection{Verbos derivados.}

$O$ verbo derivado de raiz substantiva implica a atividade tipica que se pode fazer com o referente da raiz substantiva:

Bros o i - agir com a escova: escovar.

$$
\frac{\bar{E} \overline{A_{2}}}{E}-
$$

Novamente interfere a variante vazia:

Bros $\phi$ i $\quad$ brosi.

\subsubsection{Advérbios derivados.}

$\mathrm{O}$ advérbio derivado tem significado variado, dependendo da classe semântica da raiz substantiva:

$$
\begin{aligned}
& \text { Nokt o e - de noite. } \\
& \text { Hejm o e - em casa (no lar). } \\
& \text { Bros o e - com a escova. } \\
& \frac{\bar{E} \overline{A_{2}}}{E} \overline{A_{2}}
\end{aligned}
$$

A execução da língua nos fornece novamente as formas com variante vazia: 
Nokte.

Hejme.

Brose.

\subsection{Raiz adjetiva.}

A raiz adjetiva deriva substantivos, verbos e advérbios.

3.2.1 Substantivos derivados.

O substantivo derivado de adjetivo sugere a noçāo genérica do significado adjetivo:

Alt a $0 \quad$ - o alto (ex.: o alto do morro).

E $A_{2}$

E $\overline{A_{2}}$

A variante vazia reaparece:

Alto.

3.2.2 Verbos derivados.

$\mathrm{O}$ verbo derivado implica uma intransitividade com sig. nificado de estado:

$\frac{\frac{U \text { til }}{\mathrm{E}}{\frac{\mathrm{a}}{\mathrm{A}_{2}}}^{\mathrm{E}}}{\mathrm{A}_{2}}$

- ser útil, prestar.

A execução da língua nos oferece a forma com variante vazia:

Utili.

3.2.3 Advérbios derivados.

$O$ advérbio derivado implica o modo ou a intensidade:

Util a e - utilmente.

$\frac{\bar{E} \overline{A_{2}}}{E} \frac{}{A_{2}}$

A forma da execução da língua é a seguinte: Utile.

3.3 Raiz verbal.

A raiz verbal deriva substantivos, adjetivos e advérbios com significado nitidamente determinado. 
3.3.1 Substantivos derivados.

O substantivo derivado de raiz verbal indica sempre a atividade relativa ao referente verbal:

Romp i o

$\frac{\bar{E} \overline{A_{2}}}{E} \overline{A_{2}}$

Manifesta-se evidentemente a variante vazia:

Rompo.

3.3.2 Adjetivos derivados.

$O$ adjetivo derivado implica a pertinência:

Nutr i a

- relativo a nutrir: nutritivo.
- ato de quebrar: rompimento, quebra.

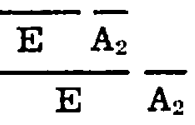

Esta é a forma da execuçāo da língua:

Nutra.

Outro exemplo:

Rompa (letero) - (carta) de rompimento.

3.3.3 Advérbios derivados.

$\mathrm{O}$ advérbio derivado indica $\mathrm{o}$ instrumento:

Far i e ( $r=r r$ ) - por parte de (feito por).

$\overline{\mathrm{E}} \overline{\mathrm{A}_{2}}$

$$
\mathrm{E} \overline{\mathbf{A}_{2}}
$$

Interfere a variante vazia:

Fare.

Um exemplo dentro de um contexto maior:

Dissendo de cirkulero fare de organizantoj.

Ou seja:

Distribuição de uma circular por parte de organizadores.

3.4 Raiz adverbial.

A raiz adverbial tem o comportamento morfológico da raiz adjetiva. 
3.5 Recursividade da derivaçāo.

A derivação é recursiva:

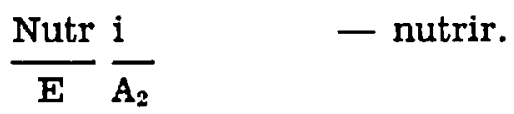

$$
\begin{aligned}
& \text { Nutr i o - ato de nutrir: nutriçāo. } \\
& \frac{\overline{\mathrm{E}} \overline{\mathrm{A}_{2}}}{\mathrm{E}} \overline{\mathrm{A}_{2}}
\end{aligned}
$$

Ou seja, com a variante vazia:

Nutro.

Nutr i a - relativo a nutrir: nutritivo.

$$
\frac{\bar{E} \overline{\mathbf{A}_{2}}}{\mathbf{E}} \overline{\mathbf{A}_{2}}
$$

Ou seja, com a variante vazia:

Nutra.

Nutr i o a - relativo a nutrição: nutricional.

$$
\frac{\frac{\bar{E} \overline{A_{2}}}{E} \overline{A_{2}}}{E}-
$$

Ou seja:

Nutra.

Aparece-nos com isso uma ambiguiidade:

Nutra

- nutritivo.

Nutra $_{2}$

- nutricional.

Essa ambiguiidade se desmancha no contexto maior:

Nutra substanco ( $c=t s)$ - substância nutritiva.

Nutra komisiono - comissão de nutrição.

A recursividade derivacional fica proibida sempre que o derivado é igual à forma primitiva por coesão:

a) Forma primitiva por coesão:

$$
\frac{\text { Bros }}{\mathrm{E}} \frac{\mathrm{O}}{\mathrm{A}_{2}}
$$


b) Forma derivada (substantivo derivado de verbo): Bros o i o - ato de escovar.

$$
\frac{\frac{\bar{E} \overline{A_{2}}}{E} \overline{A_{2}}}{E} \overline{A_{2}}
$$

Ou seja, com duas variantes vazias:

$\mathrm{BrosO}_{2}$.

A forma / broso $_{2} /$ fica rejeitada na execução da língua por colidir com a forma primitiva $/$ broso $_{1} /$.

3.6 Importância da categoria da raiz.

A classe da raiz é importante porque apenas com ela se pode prever o significado dos derivados:

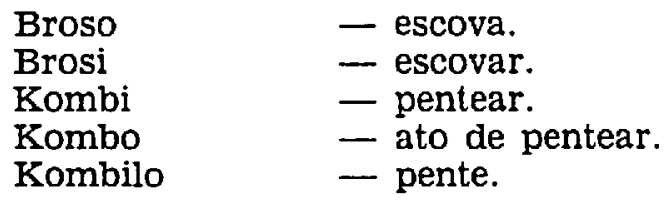

Se a raiz é verbal, o nome do instrumento deve ser derivado mediante outra raiz, chamada sufixo na Gramática Tradicional:

Komb il o - instrumento de pentear: pente.

$$
\mathrm{A}_{1} \overline{\mathrm{E}} \overline{\mathrm{A}_{2}}
$$

O mesmo ocorre com raízes substantivas e adjetivas:

$\begin{array}{ll}\text { Famo } & \text { - fama. } \\ \text { Fama } & \text { - famoso. } \\ \text { Bigoto } & \text { - (um) carola. } \\ \text { Bigota } & \text { - carola (adj.). } \\ \text { Bela } & \text { - belo. } \\ \text { Beleco } & \text { - devoto (adj.). } \\ \text { Devota } & \text { - (um) devoto. } \\ \text { Devotulo } & \end{array}$

$O$ adjetivo procede diretamente do substantivo, mas $o$ inverso postula outras raizes, novamente chamadas sufixos pela Gramática Tradicional:

Bel ec o - qualidade de ser belo: beleza.

Devot ul o - pessoa devota: (um) devoto. $\mathbf{A}_{1} \overline{\mathbf{E}} \overline{\mathbf{A}_{2}}$ 
4. Anomalias lexicais.

O dicionário oficial (Universala Vortaro) contém várias irregularidades, que retratam apenas erros de teoria, nunca de língua. Essas anomalias implicam, entretanto, uma dificuldade de aprendizagem da língua, dado que os livros didáticos trazem primeiro a palavra na classe que lhe ex atribuida pelo dicionário oficial, obrigando com isso o aluno a um duplo esforço de memória, porque o significado da forma derivada é irregular e deve por isso ser aprendido como palavra nova, além de constituir também uma irregularidade morfológica na língua.

\subsection{Raizes adverbiais.}

As raizes adverbiais poderiam ser com facilidade incorporadas às adjetivas, ainda que a sua classificação não provoque irregularidade: entretanto, obrigam a uma nova série de processos derivacionais, que podiam evitar-se dado o comportamento adjetivo dessas raizes.

De resto, são poucas:

$\begin{array}{ll}\text { Nepr e } & \text { - necessariamente. } \\ \text { Prunt e } & \text { - por empréstimo. } \\ \text { Volont e } & \text { - de boa vontade. }\end{array}$

\subsection{Raizes verbais.}

A maior anomalia reside na classificação de algumas raizes, cujo sistema derivacional implica raízes substantivas, nunca verbais.

\subsubsection{Substantivo derivado irregular.}

O substantivo derivado de verbo deve ter o significado da atividade correspondente.

São, pois, regulares:

Rompi

Rompo

Sendi

Sendo
- romper.

- rompimento.

- enviar.

- envio.

São, entretanto, irregulares:

Doti

Doto

Flori

Floro

Honori

Honoro
- dotar.

- dote, e não o ato de dotar.

- florescer.

- flor, e năo o ato de florescer.

- honrar.

- honra, e não o ato de honrar. 


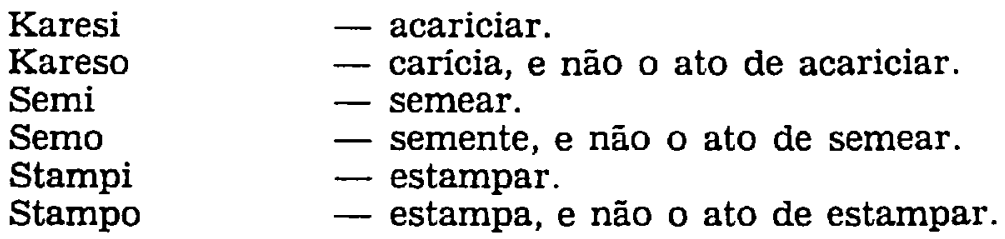

Postula-se por isso uma retificaçāo da teoria aplicada, bastando para isso tomar por substantiva a raiz dessas palavras. A derivação torna-se regular:
Semo
- semente.
Semi
- agir com a semente: semear.

\subsubsection{Adjetivo derivado irregular.}

Pode-se derivar o adjetivo diretamente do verbo, mantendo o derivado o sentido ativo, ou derivá-1o do substantivo já derivado, provocando uma ambiguiidade:

Konstrui

- construir.

Konstrua

- construtivo.

Exemplo:

Konstrua kritiko - critica construtiva.

Aparece um homônimo com a derivação que parte do substantivo:

Konstruo

- ato de construir: construção.

Konstrua

- de construção.

Exemplo:

Konstrua firmao - firma de construçāo.

Uns poucos verbos carecem dessa regularidade e apresentam um adjetivo tipicamente passivo, impossivel de justificar-se com o processo derivativo regular:
Fiksi
Fiksa
- fixar.
Konfuzi
- fixo.
Konfuza
- confundir.
Miksi
Miksa
- confuso.
- misturar.
- misto.

Se a esses verbos correspondesse também o adjetivo homônimo, derivado diretamente do verbo com significado ativo, nada se poderia objetar porque se trataria de uma homonímia inerente à língua: adjetivo derivado de verbo e adjetivo derivado de substantivo derivado de verbo. Esse adjetivo homónimo, entretanto, inexiste em Esperanto. 
Novamente, se tomarmos por substantiva a raiz pretensamente verbal, o processo derivativo torna-se coerente:

Konfuzo

Konfuza

Konfuzi
- confusão.

- relativo a confusão: confuso.

- agir com confusão: conîundir.

E preciso considerar que apenas a língua do Fundamento do Esperanto é intocável, devendo-se corrigir os desvios puramente advindos da aplicação de uma teoria lingüistica ultrapassada. Um deles pode ser retificado pela simples mudança da classe gramatical de algumas raizes verbais.

Obs.: Este artigo foi lido e debatido num simpdsio da Sociedade Brasileira de Professores de Linguiistica durante a Reunião Anual da Socicedade Brasileira para o Progresso da Ciência, realizada em Belo Horizonte, em julho de 1985.

\section{RESUMO}

Esperanto estas artefarita lingvo, enkondukita en la mondon en 1887. En la unua esperantista kongreso en Bulonjo-sur-Maro, en 1905, la partoprenantoj vochdonis la Bulonjan Deklaracion: estis akceptita la netushebleco de la Fundamento de Esperanto, kiun konsistigis kvinlingva gramatiko, ekzercaro kaj vortaro. La konsento persistas ghis nun, sed tiu Fundamento de Esperanto enhavas du diferencajn partojn:

a) lingva enhavo.

b) gramatika enhavo.

Dum la lingva enhavo estas neatakebla kaj respektenda, la gramatika enhavo, redaktita en la fino de la pasinta jarcento, devas esti aktualigita. Nia artikolo analizas unu el la eraroj de tiu gramatika cnhavo, kiu speguligas en la oficialan vortaron, sed neniel en la lingvon mem. La korektado de tia misinterpreto faciligos la lingvoakiron sen ia modifo de la lingvo, char la eraro tusas la teorion, ne la lingvon.

\section{REFERENCIAS BIBLIOGRAFICAS}

1 KALOCSAY, K. La gramatika karaktero de la Esperantaj radikoj (teorio kaj praktiko). Budapest, Literatura Mondo, 1938.

2 SZERDAHELYI, I. Vorto kaj vortelemento en esperanto: Kuopio, Literatura Foiro, 1976. 